\title{
Scotland's industrial water use: Understanding recent changes and examining the future
}

\author{
Grant J. Allan ${ }^{\dagger *}$ Scott J. McGrane ${ }^{\dagger} \quad$ Graeme Roy $^{\dagger} \quad$ Thomas M. Baer $^{\ddagger}$ \\ ${ }^{\dagger}$ Fraser of Allander Institute and Department of Economics, University of \\ Strathclyde, Glasgow, United Kingdom \\ ${ }^{\ddagger}$ Applied Physics, Stanford University, Palo Alto, California, USA
}

\begin{abstract}
Future climate scenarios predict significant changes in the availability of water resources at global and regional scales. Knowledge of the possible economic consequences of this are limited by a shortage of data linking economic activity with physical water use. Matching a unique premise-level dataset to economic indicators at industrial/sector level, this paper undertakes a decomposition of changes in industrial water demand for Scotland between 2012 and 2016. Results highlight the importance of taking a sectoral approach, as changes in sectoral water intensity are significant. Furthermore, changes in the structure of the economy, i.e. a move away from water-intensive industries, highlight further reductions in overall water consumption. By considering future scenarios for Scottish water resources, this paper identifies key multi-disciplinary research challenges to address the major obstacles in developing a climate-ready water policy, which also captures the potential economic opportunities for Scotland from an awareness of the role of water in the economy.
\end{abstract}

Keywords: Industrial water use; Index Decomposition Analysis; economy-wide analysis; Scotland.

\footnotetext{
${ }^{*}$ Corresponding author. Address: Department of Economics, University of Strathclyde, Sir William Duncan Building, 130 Rottenrow, Glasgow G4 0GE, Scotland, UK; Phone: +44 (0) 141548 3838, grant.j.allan@strath.ac.uk
} 


\section{Introduction}

The changing global climate is particularly manifesting through changes in the availability of water resources. Markandya (2017, p.1) notes that "water is the central driver of the impacts of climate change on society" ${ }^{1}$. Water is fundamental to daily human activities, while also playing a pivotal role in economic activity, such as agricultural irrigation, cooling in power stations, inputs to commercial and industrial processes, and high-value manufacturing activities.

It is at the national and regional levels that policies to adapt and mitigate changes in water availability will be implemented ${ }^{2}$. Developments in new housing, protection of existing economic assets, and developments in necessary infrastructure will require policy-makers to have the best advice on the consequences of changing water availability. For these reasons, an initial understanding of the way in which water is used in the economy becomes vital. There is a global need to understand the regional variations in resource availability and consumption patterns, helping to identify areas that are especially vulnerable to changes in available water resources. Many goods and services we consume originate in water-stressed regions, whereby significant variations in the availability of freshwater will have global consequences for the production, trade and value of certain products. Current modelling capacity for regional geographies are often hindered by a lack of available data, resulting in highly uncertain simulations of future changes being used by resource managers, decision makers and policy-makers. Tackling this issue will require a global-scale mobilisation of multidisciplinary researchers, combining environmental science, policy makers, private sector concerns around risk and resilience,

\footnotetext{
${ }^{1}$ Climate change will impact the spatiotemporal distribution of water resources by altering the natural dynamics of the hydrological cycle (including precipitation, evaporation, infiltration and runoff) and changing regional water balances. Furthermore, hydrological extremes such as droughts and floods will transmit socioeconomic challenges such as destruction of property and infrastructure, reductions in crop yields and diminished food security) with associated increasing food costs), reduced access to freshwater resources and the resultant challenges this will pose for water-intensive sectors.

${ }^{2}$ Robins et al. (2017) describes the complex interactions in water-governance in the UK, for instance, while Kampragou et al. (2011) describes how local and national plans for drought management should be prioritized within the EU.
} 
and regional authorities responsible for the provision and maintenance of critical water delivery infrastructure.

While the freshwater balance of Scotland typically ensures sufficient supply to sustainably meet domestic and non-domestic demand, periods of drought or low rainfall can have significant impacts on the availability of freshwater and resulting demand. During the summer of 2018, a prolonged period of dry conditions resulted in increases in water being used for irrigation by farmers, particularly in the East of the country. In such circumstances, water scarcity presents a challenge to continued sustainable consumption of water resources, and can impact the operation and efficacy of many economic activities. The effects of seasonal changes in climate variables in Scotland are becoming increasingly evident: between 1961 and 2004, Scotland experienced a 20\% increase in annual average precipitation, driven by a large increase $(+50 \%)$ in winter precipitation (Barnett et al., 2006). This is driven, in part, by an increasing thermal gradient that is reducing the precipitation falling as snowfall and being stored in upland snowpacks, released during melt events into the warmer spring months. This poses a significant water availability issue for sectors that rely on flows at certain times of the year.

The UK Climate Projections published in 2018 highlight many of the challenges that face Scotland as a consequence of climate change (Lowe et al., 2018). Indeed, many of these impacts are already being observed, with increasing temperatures, wetter winters and drier summers having occurred in the past few decades compared to long term averages (Barnett et al., 2006). Nationally, warmer mean temperatures will continue to experience increases annually, with Winter and Spring temperatures in particular project to experience significant increases. While this has potentially positive consequences for sectors such as agriculture (by extending the growing season in late winter and early Spring), the increase will impact melt-dynamics of upland snowpacks and result in earlier runoff events across hydrological systems. Rainfall is project to experience seasonal fluctuations: generally speaking, summer months will become drier in the South and East 
of the country, whereas Autumn and Winter months will experience wetter conditions. The concentration of agricultural activities in the south and east will necessitate the use of water resources for irrigation of critical crops and livestock, significantly increasing the water footprint of domestic agricultural production.

In this paper, we bring together a unique database of premise level water use and economic indicators at the sectoral level, and perform the first Index Decomposition Analysis (IDA) applied to industrial (i.e. non-domestic) "blue" water use in Scotland, covering the period between 2012 and 2016. Our measure of water use refers to that from the "mains" public supply - commonly termed "blue" water , e.g. Mekonnen and Hoekstra (2011)) - in businesses located in Scotland, i.e. across the whole country ${ }^{3}$. In doing so, we contribute to the existing literature in two primary ways.

First, there are a very limited number of applications of decomposition techniques to the analysis of water use ${ }^{4}$. The limited application of decomposition techniques may in part reflect: a lack of available water use data at the sectoral level; various holders of water consumption data across a region with no agreement on data sharing; and little prior interest in water issues in water-abundant developed countries (Duarte and Yang, 2011). Indeed, only four examples of decomposition applied to water use are known to the authors: Cazcarro et al. (2013) use SDA to analyse changes in water consumption in Spain between 1980 and 2007, while Shang et al. (2017b) and Shang et al. (2017a) use the Laspeyres and Log Mean Divisia Index (LMDI) models to decompose industrial water use in Tianjin, China. Kohler (2016) decompose water use in South Africa between 1980 and 2012 - using the Fishers index - between a structural effect and an intensity

\footnotetext{
${ }^{3}$ We do not have information on private abstractions of water in the Scottish economy. Such uses are however likely to be small in absolute terms - only around $5 \%$ of business premises are not connected to the mains public supply, and supplied by the organisation from whom our water use data is provided. Our measure of industrial water use from main supply however is the total amount of supply for which public infrastructure is developed, and is critical to understanding from both a water management and economic development perspective.

${ }^{4}$ By "decomposition techniques" we have in mind both IDA and Structural Decomposition Analysis (SDA). We outline the elements of each below and focus on IDA approaches in this paper.
} 
effect ${ }^{5}$.

Second, in applying the Log Mean Divisia Index (LMDI) technique to Scotland, we perform the first analysis of IDA for a water-abundant developed region ${ }^{6}$. In Scotland, water is an abundant resource and characterises many emblematic activities, including being an integral component of whisky production, aquaculture and hydroelectric dams and reservoirs.

Scotland additionally makes an interesting application for a number of reasons. Scotland's freshwater resources account for c. $2 \%$ of the total land surface, with over 50,000 $\mathrm{km}$ of rivers and over 30,000 lochs (Ferrier and Edwards, 2002). The majority of Scotland's critical freshwater supply reservoirs are located in the west of the country, where rainfall is significantly higher than in the east. This water is distributed to end-users, the vast majority of whom are concentrated in the central (south and east) region of the country, resulting in an extensive distribution network connecting storage reservoirs to end-users. Water use varies across Scotland: agriculture is primarily rain-fed, meaning piped supply for agricultural use is small compared to other parts of the United Kingdom. The largest element of public water supply in Scotland services domestic demands (c.42\% in 2016/17), with non-domestic (i.e. industrial) consumption comprising around $22 \%$ of total treated water produced ${ }^{7}$.

Population growth in Scotland continues at a slow rate, declining from $0.6 \%$ growth in 2016 to $0.2 \%$ growth in 2018 (National Records of Scotland, 2018), so domestic demand for freshwater has grown at a manageable rate accordingly. In recent years, there

\footnotetext{
${ }^{5} \mathrm{Xu}$ et al. (2015) and Zhao et al. (2017) use the IDA (specifically, LMDI) approach, and Zhang et al. (2012) use SDA to decompose changes in the water footprint of Beijing and Suzhou City respectively. These do not separately identify water use at the national level, but includes water contained in products produced outside those areas, and embodied in the consumption patterns of each city. We only focus on domestic factors influencing water demand in Scotland, and discuss extending the analysis to the use of footprint measures in Section 6.

${ }^{6}$ A SDA analysis between 2012 and 2016 was beyond the scope of this paper at time of writing due to the unavailability of Input-Output tables for 2016.

${ }^{7} \mathrm{~A}$ total of 1,785 Million litres per day is produced by Scottish Water, with the remaining portion comprising that used for Scottish Water's operational purposes (3\% of total) and leakage (31\% of total (Scottish Government (2017a)).
} 
has been a population shift from the west of the country to the east, as new housing developments and more job opportunities in cities like Edinburgh, Aberdeen, Dundee and Perth have emerged. Due to the orographic effects of the elevated west coast, the majority of rainfall lands in the west of the country, where the majority of water supply reservoirs and hydroelectric facilities are concentrated. This presents a disconnect between resource availability and demand, necessitating significant infrastructure to ensure water is available to a growing population furthest from the main sources of freshwater. In spite of the ratio of people to available resources (approximately $15,000 \mathrm{~m}^{3}$ of water per person and year (Marsh and Anderson, 2002)), Scotland's vast resources are under increasing threat from variable rainfall patterns as a result of global climate change. This results in a need to better understand and improve the way water is used, managed and governed (Werritty, 2002).

A notable step in Scottish Government policy towards water resources was the publication in 2012 of the Hydro Nation programme (Scottish Government, 2012). This explores how Scotland's natural resource and availability of water might be employed to its economic advantage, for instance through the production of water-intensive products. As such, a fundamental starting point is to understand existing links between economic activity and water consumption in Scotland. Claret et al. (2018, p.36) also identify that Scottish policymakers have sought to implement the ecosystem services approach into policy, however this has been limited in practice due to, "gaps in available and accessible data and more generally in the evidence base for the design of appropriate instrument[sic]".

Additionally, the latest's Government Economic Strategy notes the central economic role of the transition to a more resource-efficient economy (including water) and their strategy for growth: "reducing the cost to the Scottish economy of climate change, while maximising opportunities to export our technology innovations and knowledge as other economies make their own low carbon transition" (Scottish Government, 2015, p.45). 
Further, there is also a critical role for developments in the energy sector, specifically electricity, which contribute to changes in the profile for water use. With ambitious targets for renewable electricity (e.g. Scottish Government (2017b)), these will have consequences not only for Scotland's economy and emissions, but also water use.

This paper is structured as follows. Section 2 outlines the IDA approach which is employed in this study, and provides previous examples of IDA to water issues, while Section 3 details the sources of the data used in this paper. Section 4 provides results, and Section 5 provides forward-looking context to our findings, and the scale of climate and technological factors affecting the availability and use of water in Scotland. Section 6 provides conclusions and recommendations for further research.

\section{Methods}

\subsection{General framework}

While Index Decomposition Analysis (IDA) techniques have been used since the 1970s, there has been rapid recent growth in the number of applications. Wang et al. (2017) notes that more economy-wide IDA studies were published between 2009 and 2017 (120) than in the previous 30 years (110). Standardisation of IDA approaches has coincided with a rapid expansion of the application of these approaches within international and national agencies (Ang, 2015). IDA analysis offers the ability to assess the driving forces behind aggregate measures of environmental impact, e.g. energy use or pollution (Wang et al. 2017). These papers have shown an increasing focus on energy or emissions measures, and applications taking multi-level regional and geographic analysis into account.

Setting out the IDA framework, Wang et al. (2017) generalise an aggregate indicator $(V)$ into $m$ entities and the product of $n$ factors $(x)$, i.e.:

$$
V=\sum_{j=1}^{m} V_{j}=\sum_{j=1}^{m}\left(\prod_{i=1}^{n} x_{j, i}\right)
$$


In pratice, most IDA studies typically use (at least) three factors, such as the level of economic activity, the sectoral structure of production and a factor relating environmental or energy features to economic activity at the sectoral level. Changes in aggregate variable, $V$, between period 0 and $\mathrm{T}$ can be expressed as either additive or multiplicative effects. In the former:

$$
V^{T}-V^{0}=\sum_{j=1}^{m} x_{j, 1}^{T} x_{j, 2}^{T} \ldots x_{j, n}^{T}-\sum_{j=1}^{m} x_{j, 1}^{0} x_{j, 2}^{0} \ldots x_{j, n}^{0}
$$

so that an additive effect for each factor can be identified ${ }^{8}$, e.g.:

$$
V^{T}-V^{0}=\Delta V_{1}+\Delta V_{2}+\ldots+\Delta V_{n}
$$

In principle there are a number of alternative IDA specifications ${ }^{9}$ with divisia-linked approaches becoming more dominant; specifically, the LDMI approach is commonly observed (Wang et al., 2017). LDMI has been argued to be a superior IDA approach (Ang, 2004), as it satisfies all of the key desirable properties for a decomposition approach, including 1) a perfect decomposition (i.e. does not result in a "residual" element), 2) it is robust to negative or zero values, and 3) and is straightforward to implement and explain to non-specialists (Wang et al., 2017).

The factors typically used in LDMI techniques permit the decomposition of change in the aggregate indicator, $V$ into three elements. First, an "activity" effect, relating to

${ }^{8}$ In the latter, changes in $V$ are derived as:

$$
\frac{V^{T}}{V^{0}}=\frac{\sum_{j=1}^{m} x_{j, 1}^{T} x_{j, 2}^{T} \ldots x_{j, n}^{T}}{\sum_{j=1}^{m} x_{j, 1}^{0} x_{j, 2}^{0} \ldots x_{j, n}^{0}}
$$

with the multiplicative elements:

$$
\frac{V^{T}}{V^{0}}=D_{1} D_{2} \ldots D_{n}
$$

Where $D_{n}$ refers to the multiplicative effect for the $n$-th factor.

${ }^{9}$ Wang et al. (2017) present Laspeyres, Paasche and Divisia-Linked approaches to decomposition for instance. 
that portion of the change in $V$ caused by changes in the size of the economy. Second, the "structural" effect, explaining the portion explained by the changing industrial mix over the time period, and finally, the "intensity" effect, noting the contribution of changes in sectors use of the aggregate indicator per unit of output of that sector (i.e. for water, this would relate to changes in the sectors use of water per unit of output, or "water-intensity" ${ }^{10}$. Wang et al. (2017, p.593), reviewing applications of IDA to energy and emissions, suggests that the intensity effect (Eq.7) has particular policy relevance: "since promoting energy efficiency to reduce energy use and emissions has been a policy measure of great practical significance."

Shang et al. (2017b) applied both a refined Laspeyres method and an LDMI approach to industrial water use in Tianjin, China between 2003 to 2012. Their measured "Industrial water" refers to water used in the production process, including "surface water, groundwater, recycled water and desalinated water, and does not include directly used seawater" (Shang et al., 2017a, p.59), and so matches broadly with our own measure, which we discuss in Section 3. Their results found that economic activity largely stimulated industrial water use after 2008 - consistent with a period of rapid growth. Technology effects, on the other hand, served to reduce water demand particularly in the early period of their analysis, but making a smaller contribution to reducing use as intensity improvements (reductions) plateaued from 2008 onwards.

Shang et al. (2017a) undertook a refined Laspeyres analysis of industrial water use in Tianjin, producing results with greater detail on the sectoral contribution to each of the observed effects (structural, activity and technology). They note that the intensity("Technology") driven changes "are negative, indicating that in the study period, water efficiency improved; but some exceptions within a few industrial sectors during specific time periods are attributed toimproper management or ignorance of water saving" (Shang et al., 2017b, p.1146). In particular they identified the critical role for the ag-

\footnotetext{
${ }^{10}$ Shang et al. (2016) refer to these respectively as the "Output", "Structure" and "Technology" effects respectively.
} 
gregate results of water-intensive sectors, including electricity production and chemicals and steel manufacturing activities. The authors also argue that their analysis shows the way in which "reducing industrial water use is not a primary target, but a companion product of industrial development and industrial restructuring" (Shang et al., 2017b, p.1146).

The technique of Structural Decomposition Analysis (SDA) dates from the 1980s, developing in parallel to (but independently of) the IDA literature (e.g. Hoekstra and Van den Bergh, 2003; Su and Ang, 2012). Gowdy and Miller (1987) is identified by Wang et al. (2017) as an early example of SDA to energy use in the USA ${ }^{11}$. SDA is a comparative-static technique, like IDA, however differs in the use of an Input-Output (IO) framework (Cazcarro et al., 2013, p.52). SDA uses the inter-sectoral detail of purchases and sales provided by IO models, permitting the detailed analysis of intersectoral links to be considered in the decomposition process.

While the application of IDA has been broader than SDA - including both industryspecific and economy-wide analysis - recent applications of IDA have increasingly been at the economy-wide level (Wang et al., 2017). The IDA and SDA approaches have also been critically compared by Hoekstra and Van den Bergh (2003) and Su and Ang (2012). The SDA approach permits a more detailed disaggregation of changes compared to the IDA approach, however this requires a greater volume of data (at least two annual IO tables linking sectoral economic activity to environmental measures e.g. emissions, water use or energy use).

\subsection{LDMI decomposition}

We define total industrial water use $-Q$ - in a specific year $t$ as the combination of three factors:

\footnotetext{
${ }^{11}$ Extensive references for applications since the 1970s, as well as reviews of the SDA literature are given in Miller and Blair (2009). Early reviews of the SDA and IDA approaches are provided in Rose and Casler (1996) and Ang and Zhang (2000) while a recent excellent review of applications of IDA and SDA to energy use and emissions is provided in Wang et al. (2017).
} 


$$
Q^{t}=\sum_{i=1}^{n} Q_{i}^{t}=\sum_{i=1}^{n} M^{t} \times \mu_{i}^{t} \times q_{i}^{t}=\sum_{i=1}^{n} M^{t} \times \frac{M_{i}^{t}}{M^{t}} \times \frac{Q_{i}^{t}}{M_{i}^{t}}
$$

where $M$ is economic output, $n$ is the number of sectors, $\mu_{i}$ is sector $i$ 's share in total economic output and $q_{i}$ is sector $i$ 's water intensity, i.e. $Q_{i} / M_{i}$.

We can then decompose changes in water use between years 0 and $T$, i.e. $Q^{T}-Q^{0}$ into three elements: that which is due to changes in the size of the economy $\left(Q_{m}\right.$, the "activity effect"); that which is due to changes in economic structure $\left(Q_{\mu}\right.$, the "structural effect"); and the contribution of changes in sectoral water intensity ( $Q_{q}$, the "intensity effect" $)^{12}$.

$$
Q^{T}-Q^{0}=\Delta Q=\Delta Q_{m}+\Delta Q_{\mu}+\Delta Q_{q}
$$

where:

$$
\begin{aligned}
\Delta Q_{m} & =\sum_{i=1}^{n} \frac{Q_{i}^{T}-Q_{i}^{0}}{\ln Q_{i}^{T}-\ln Q_{i}^{0}} \ln \frac{M_{T}}{M_{0}} \\
\Delta Q_{\mu} & =\sum_{i=1}^{n} \frac{Q_{i}^{T}-Q_{i}^{0}}{\ln Q_{i}^{T}-\ln Q_{i}^{0}} \ln \frac{\mu_{i}^{T}}{\mu_{0}^{T}}
\end{aligned}
$$

and

$$
\Delta Q_{q}=\sum_{i=1}^{n} \frac{Q_{i}^{T}-Q_{i}^{0}}{\ln Q_{i}^{T}-\ln Q_{i}^{0}} \ln \frac{q_{i}^{T}}{q_{0}^{T}}
$$

\section{Data}

We use water consumption data in $m^{3}$ for all non-domestic premises in Scotland between the financial years 2011-12 and 2016-17. Data cover usage from the mains

\footnotetext{
${ }^{12}$ Ang (2015) provide great detail on the options available for carrying out a decomposition using LMDI approaches.
} 
system, and relates to actual consumption at the meter level, and so excluding water from rainfall, private abstractions, sea water, and river-fed irrigation (see footnote 3 for more detail on the water use measure used in the analysis).

Premise/meter level data was provided by Scottish Water, with an industrial classification representing the industry to which each premise related. A detailed analysis of the provided industrial codes was undertaken for a sample of premises to consider the appropriateness of its classification and correct for any mis-classifications, as well to convert all classifications to a common Standard Industrial Classifications basis (SIC 2007). This was necessary to allow a reconciliation of the water data to sectoral economic data on Scotland's Gross Value Added (GVA) gathered on the same basis. The level of sectoral disaggregation in the quarterly GVA index series for Scotland determines the level of economic detail at which the analysis can be undertaken ${ }^{13}$.

Figure 1 shows the evolution of Scottish GVA and non-domestic water demand at an aggregate level between 2012 and $2016^{14}$. Over the period, Scottish GDP grew at an average annual rate of $1.7 \%$, and non-domestic water demand fell by $11.4 \%$. This suggests a decoupling of water demand from aggregate economic activity over this period, for the water variable considered. The water intensity of aggregate Scottish economic activity - water use per $£$ - fell by $17.2 \%$ over this period. Averaged over the economy as a whole, 1,290 $\mathrm{m}^{3}$ of water supported $£ 1$ million of economic activity in 2012, while in 2016 this indicator had improved (decreased) to $1,069 \mathrm{~m}^{3}$.

While there are consistent increases in economic activity, we can see that water demand decreased by a declining rate in each year, before increasing between 2015 and

\footnotetext{
${ }^{13}$ At time of writing there was no official statistics on Scottish sectoral output, so GVA is used to represent the size of each sector. This is consistent with other papers in this area, e.g. (Ang, 2015; Kohler, 2016; Shang et al., 2017b). The official quarterly GVA series for Scotland separately identifies 22 economic sectors. Economic data on a greater degree of sectoral disaggregation is produced in the annually updated Input-Output tables, however these have a longer time-lag than the GVA index series (i.e. at the time of writing IO tables were available only to 2015, with water data available to financial year 2016-17).

${ }^{14}$ In Figure 1 levels of GVA water demand and water intensity are indexed to 100 in 2012, so that changes against this starting point can be seen.
} 
2016. The increase in this final year is particularly interesting, and can be related to changes at the sectoral level, which we explore later. The decomposition analysis undertaken in this paper reveals the factors influencing this aggregate picture, and we then discuss in context of changes in the demand for and availability of water in Scotland in the future.

Figure 1: GVA, non-domestic water demand and water intensity (i.e. M/GVA) for Scotland, 2012 to 2016

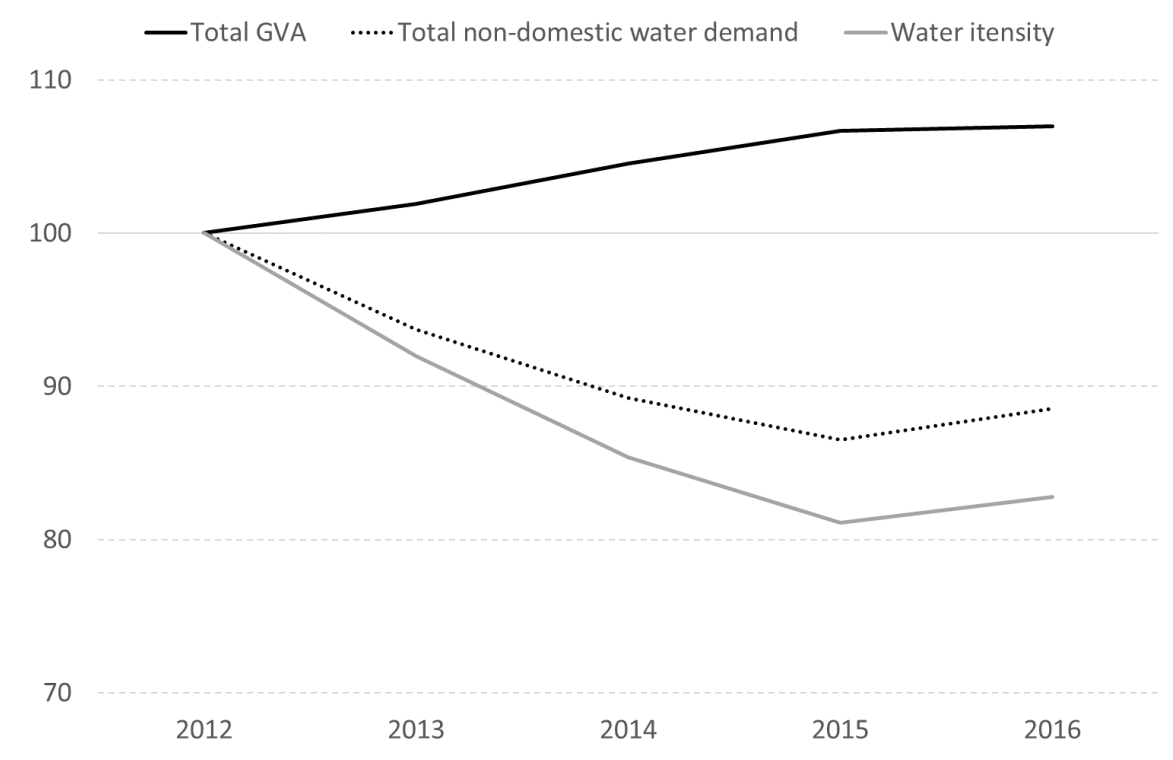

Source: Authors' calculations.

We make two further adjustments to have consistency between the (quarterly) GVA series and financial year information on water use by sector. First, we convert quarterly sectoral real GVA indexes to monetary figures by indexing to the GVA figures published in the most recent set of IO accounts for Scotland. This provides an annual series for economic activity in real terms for each sector between 2012 and 2016. Second, we convert water use data aggregated at 22 sectors to a calendar basis ${ }^{15}$. Water-GVA

\footnotetext{
${ }^{15}$ We calculate sectoral water use in year $t$ from financial year figures for years $t-1$ to $t$ and $t$ to $t+1$ by assuming water demand is constant across all months of each financial year, and adjusting for the
} 
intensities for each sector in each year $\left(q_{i}^{t}\right)$ are calculated by dividing the calculated annual figure for sectoral water use by its annual GVA, and each sector's contribution to total GVA in each year $\left(\mu_{i}^{t}\right)$ calculated by dividing sectoral GVA by total Scottish GVA.

\section{[TABLE 1 AROUND HERE]}

Table 1 reveals the changes between 2012 and 2016 for GVA and the water-intensity of sectoral output. With regards to the GVA shares, we note relatively small changes over the period, which is not too surprising given the short span covered. Grouping the sectors, the share of activity in both Manufacturing (Sectors 2 to 9) and Services (Sectors 13 to 22) fell slightly over this period - down from $12.6 \%$ of GVA and $75.5 \%$ to $11.9 \%$ and $75.1 \%$ respectively. The largest change in sectoral share of GVA was seen in the "Construction" sector, increasing from $6.34 \%$ to $7.52 \%$.

Turning to the observed changes in water intensities, several features stand out. First, almost all sectors see a reduction in water intensity over this period. Only two sectors - "Water supply" and "Education" - record increases in this period, by $13 \%$ and $7 \%$ respectively. Second, some sectors see significant reductions in intensity, in both absolute and percentage terms. The two largest changes in absolute water intensity are seen in the "Agriculture" and "Refined Petroleum, Chemical and Pharmaceutical Products" sectors, while the largest percentage reductions are seen in "Computer, Electrical and Optical Products" and "Transport equipment" (both seeing water intensity fall by 47\%), the water intensity and share in output of these sectors is relatively small.

number of months in each financial year, i.e. for year 2014 , we multiply $0.25^{*}$ the sectoral value of water use for 2013-14 plus $0.75 *$ the sectoral value for water use in 2014-15. 


\section{Results}

\subsection{Decomposition: Aggregate results}

We now turn to the results of the LDMI approach outlined in Section 2. We decompose changes in industrial water demand between 2012 and 2016 into "activity", "intensity" and "structural" effects.

Figure 2: LDMI decomposition of changes in non-domestic water demand in Scotland, 2012 to 2016

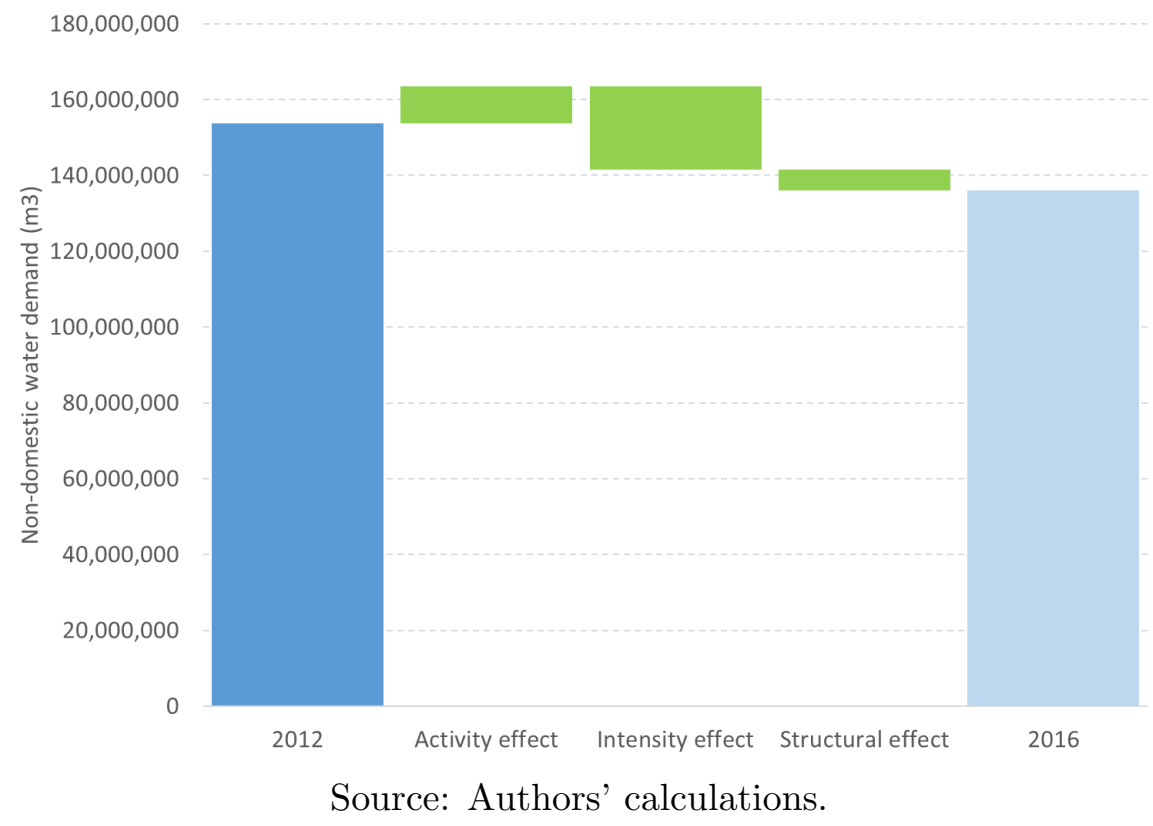

From Figure 2 we can see the relative contributions of each effect, and the direction of each effect on total water demand over this period. First, we note that the activity effect serves to increase water demand, however the impact is relatively modest, increasing water demand by $9.7 \mathrm{M} \mathrm{m}$. That is, the observed increase in economic activity over the period of our analysis would have been consistent with this increase in non-domestic water demand, holding both economic structure and sectoral water-intensity constant.

Second, the structural effect reduces water demand, but not sufficiently to offset the 
increase from the activity effect. As noted earlier there is relatively small change in economic structure over the brief span of years covered by our analysis.

Third, we see the significant contribution of the intensity effect over this period, which results in a reduction in water demand of $21.8 \mathrm{M} \mathrm{m}^{3}$. Thus, we can ascribe the major contribution to the observed reductions in industrial water demand to within sector improvements in the intensity of water use.

\subsection{Decomposition: Aggregate results by year}

In addition to our analysis over the total time period, we undertake decomposition on an annual basis. Redoing the analysis on this basis, we can identify changes in the direction and scale of each effect over time. The results of these annual calculations are shown in Figure 3.

Given the importance of the intensity effect to the overall change over this period, we can two identify further noteworthy aspects of this effect. First, we see that the intensity effect served to reduce water demand in only three of the four years of our time span. Between 2015 and 2016, this effect actually increased - a result which we explore more in the following subsection when we examine sectoral changes. Second, we can also see that the decrease in water demand assigned to the intensity effect has been reducing each year. Indeed, between 2015 and 2016 the intensity effect actually served to increase water demand.

\subsection{Sectoral analysis of the Intensity Effect}

Our results above indicate that the reduction observed in Scottish non-domestic water demand is principally explained by improvements in the water intensity of production within sectors. This therefore suggests that a focus on sectoral results is warranted. We have picked out the changes between 2015 and 2016 - which as we saw above coin- 
Figure 3: LDMI decomposition of changes in non-domestic water demand in Scotland by year, 2012 to 2016

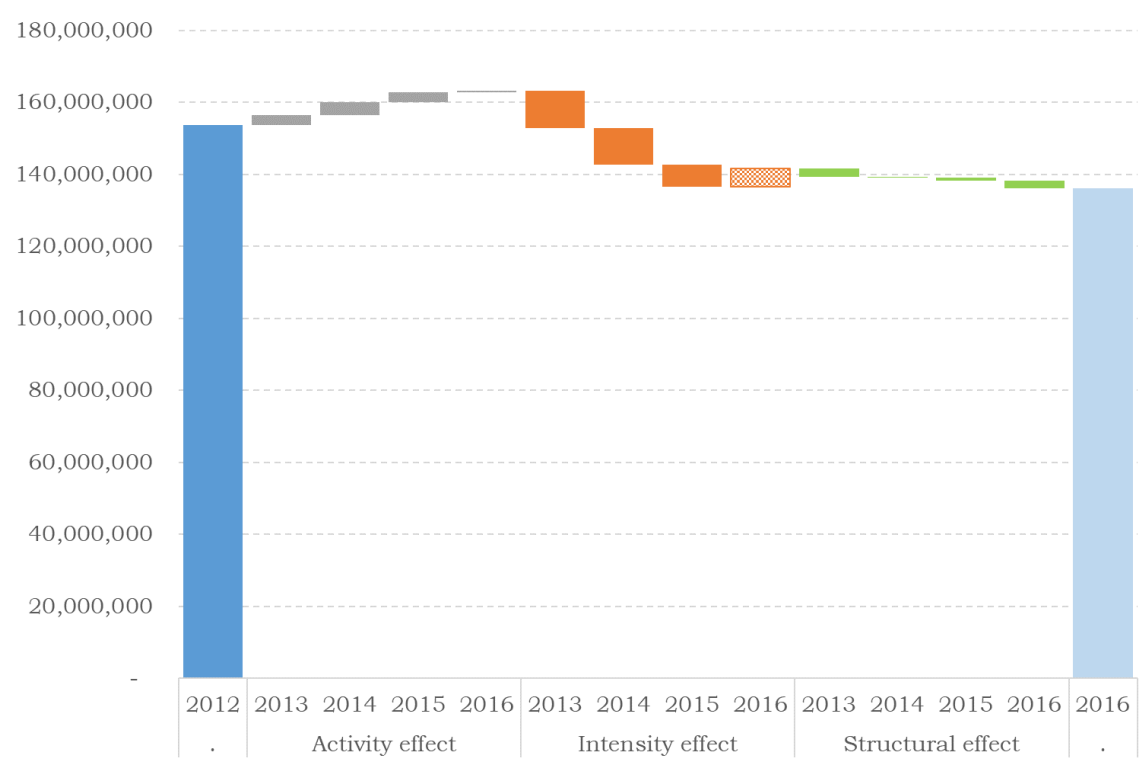

Source: Authors' calculations.

cided with an increasing contribution from the intensity effect - to focus on the relative importance of sectoral changes.

To permit a focus on the Intensity Effect, show each sectors contribution to this between 2015 and 2016 in Figure 4. In the most recent year of our period, five sectors saw increases in all three areas: their own water use, water intensity and their share in total GVA, specifically, "Agriculture, forestry and fishing", "Retail and wholesale", "Accommodation and food services", "Real estate activities" and "Professional, Scientific, Administrative and Support Services". These five sectors however did not see the largest increases in water use in this most recent year. Three sectors increased their water use by more than $1 \mathrm{M} \mathrm{m}^{3}$ : "Food, Beverages and Tobacco", "Other manufacturing" and "Refined Petroleum, Chemical and Pharmaceutical Products". We see that over the period most sectors were adding positively to water demand through the in- 
tensity effect. Of the major sectors, only Sector 10 ("Electricity and Gas Supply") had improved (reduced) its sectoral intensity of water use sufficiently to add to reductions in the intensity effect. Indeed, Figure 4 shows that total water use would have increased by more in 2016 had it not been for a reduction in water use in the "Electricity and Gas Supply" activities of just over $2.5 \mathrm{M} \mathrm{m}^{3}$.

Figure 4: Sectoral contributions to intensity effect, 2015 to 2016

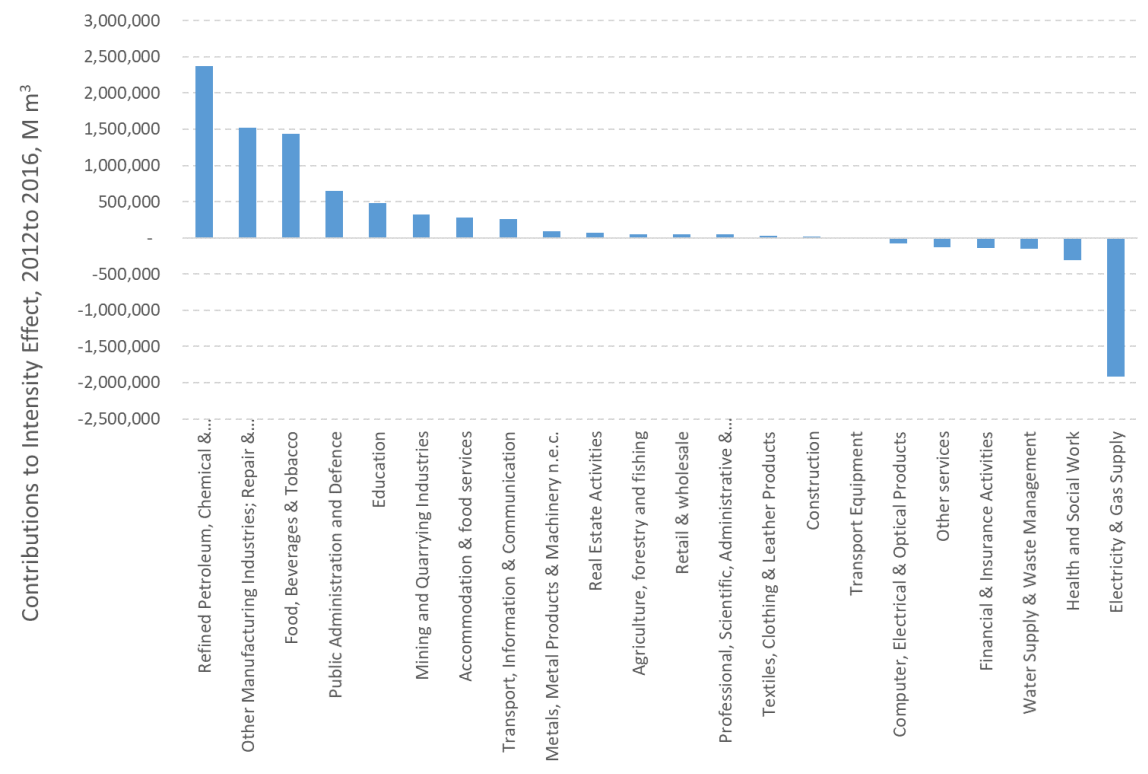

Source: Authors' calculations.

The "Food, Beverages and Tobacco" sector and the "Refined petroleum, chemical and pharmaceutical products" sector have both experienced increases in the intensity effect over the course of the four years. The food and drink manufacturing sectors underpin a significant portion of Scotland's export produce, and many sectors have witnessed substantial growth in the past few decades. In particular, the growth in craft beer manufacture in Scotland has grown significantly (229\%) since 2010, expanding from 35 breweries across Scotland to 115 (O'Connor, 2018). Furthermore, the combined 
growth in global demand for Scottish spirits (namely whisky and gin) have resulted in continued growth in this sector over the past decade. This pattern of rising water consumption in the Scottish food and drink industry is consistent with findings from Ajiero and Campbell (2018), who identify food and drink as being the largest end-user of water across industrial sectors, followed closely by chemical manufacturing. Their findings also elucidate the rising water intensity within the Scottish refined petroleum, chemical and pharmaceutical manufacturing sector. Scotland has a number of large refineries, chemical manufacturing plants and pharmaceutical manufacturing facilities that represent the single-largest end-users of water across all Scottish sectors. The production of refined petroleum in Scotland is inextricably linked to the global oil market. Indigenous production and exports of refined petroleum reduced in 2013-2015 in response to a global slowdown in the oil market prices as a consequence of growing inventories. Production increased again in 2015 and 2016, resulting in an increase in the water intensity associated with this particular sector.

Two noticeable changes to the "Electricity and Gas Supply" sector in 2016 warrant further comment. As part of Scotland's low carbon ambitions, the last decade has seen a rapid increase in renewable electricity generation, while Scotland's fossil plants have been closing. As of March 2016, the last coal power station in Scotland at Longannet closed, following the 2013 closure of the Cockenzie power station. The sharp increase in renewable electricity capacity in Scotland over the last decade - including onshore wind, hydro and solar - have had significant implications for water demand in this sector. These technologies have significantly lower water intensity than fossil technologies (e.g. Grubert and Sanders 2018). This being said, that the reduction in total water demand does not occur between 2015 and 2016, points to the importance of looking across all sectors in predicting future non-domestic water demand. We return to these issues in Section 5 . 


\section{Discussion: The future for Scotland's water}

Having examined changes in industrial water demand in Scotland between 2012 and 2016, we now turn to the outlook for the future use and availability of water in Scotland. We look at this under three perspectives; 1) the shape of future demand, 2) the future climate and water availability issues; and 3) the opportunities for sustainable economic growth around new technological applications at the sectoral and aggregate level.

\subsection{Demand perspectives}

The combined threats of population growth and climate change will increase pressures on existing finite water resources while also intensifying the hydrological cycle, resulting in increasing frequency and magnitude of extreme events and also impacting the spatiotemporal availability of water resources globally (Betts et al., 2018).

Excluding non-consumptive water use from the generation of electricity via hydroelectric power, peak demand for water is concentrated in the populous southern and eastern regions of the country, where available water resources are most limited. With Scotland's population projected to continue growing by c.5\% to 2041 (with much of it contuing to be concentrated in the central and southern regions) (National Records of Scotland, 2016), the pressure placed on regional water resources will result in challenges to water resource managers and end-users.

Currently, irrigated agriculture accounts for $90 \%$ of global freshwater usage, with electricity generation, manufacturing and domestic consumption being other primary consumers (Markandya, 2017). As the global population continues to grow, this is estimated to require an additional 55-70\% more food by 2050 to sustain global dietary requirements (Ranganathan et al., 2016), with energy usage set to increase by $80 \%$ during the same time to support an expanding economy (Organisation for Economic Development and Cooperation, 2012). As competition increases for water, combined 
with the instability in natural hydrological replenishment as a result of climate change, there will be significant pressure on water users to maximise the productivity of water, ensuring maximum output value per volume used. As a result, water-saving technologies and changes in economic processes (such as changing supply chains to reduce pressure on demand for produce from water stressed regions of the world) will be necessary to continue ensuring security of supply across the globe. In Scotland however, the water demand from agriculture is currently low, whereby the bulk of irrigation is provided by natural rainfall rather than mains water distribution systems. However, a combination of a changing climate and increased demand are resulting in changes on both the demand and supply sides (Brown et al., 2011). Furthermore, the spatial disparity in where water resources are concentrated versus the geography of high-value crops presents a further challenge to farmers and the economic significance of certain crops. As irrigation becomes increasingly necessary in the Scottish agroindustry, technologies, water management, soil and plant management and water pricing strategies developed in water-stressed agriculturally intensive regions (e.g., California, the Mediterranean) will act as a benchmark for sustainable irrigation practices in critical agricultural regions in Scotland (Chartzoulakis and Bertaki 2015).

\subsection{Water in a changing climate}

Collectively, the impacts of climate change will be most pronounced at the regional level, whereby changes to precipitation patterns, alterations to stream discharge and groundwater recharge, increasing rates of evaporation from lakes and reservoirs, and changes to the thermal gradients in snowpack-reliant regions will all manifest in changes to local water security (Henderson et al., 2015).

Future projections of climate change highlight a real need to understand what impacts regional changes may have on manufacture and trade of goods and services. Scotland's overall annual rainfall has increased since the 1970s, with current volumes around 
$13 \%$ higher than the average values observed during the early 20th century (Scottish Government, 2014). Furthermore, increasing temperatures during the winter months have resulted in reductions to low-altitude snow cover in Scotland (Trivedi et al., 2007), with precipitation instead falling as rainfall. The projections from the United Kingdom Climate Projections assessment 2018 (UKCP18) highlight complexities associated with predicting future changes to Scotland's available freshwater (Chan et al., 2018). While the general pattern of drier summers and wetter winters are already being observed and expected to intensify to 2100 , water supply and demand is regionally disparate and invariably complex (Gosling, 2014). During the winter and spring, increased temperatures will result in reduced accumulation of snow and accelerated rates of snowmelt, resulting in soil moisture deficits into the later spring months when agricultural activities intensify. Warmer temperatures combined with drier summer conditions will result in enhanced rates of evapotranspiration, resulting in water resource deficits occurring during the summer and autumn months (Brown et al., 2011). This will present a number of challenges for seasonally intensive water-users such as agriculture, food and drink manufacture and tourism, which enter their peak during the dry summer months.

The intensification of the hydrological cycle will also result in changing patterns of drought and floods in Scotland by the 2050s. Gosling (2014) projects that current 1in-40 year drought events will become approximately 1-in-20 year events by 2050 . This reduction in available resources may result in significant seasonal challenges for many of Scotland's highly productive economic sectors such as whisky production, aquaculture, forestry, hydro-power generation and agriculture, that rely on the abundance of resources that are sensitive to climatic inputs (Scottish Government, 2014). The summer of 2018 provided some insight into what reduced rainfall conditions could mean for some regions of Scotland. Precipitation in north east Scotland was only $67 \%$ of long-term averages, resulting in water-use restrictions across the Morayshire region of the country (Hannaford, 2018). As climate change intensifies these changes to the hydrological cycle in 
Scotland, the availability of water in specific regions may vary dramatically and impact the economic activities of particular regions or sectors of the economy.

\subsection{Technological developments and sectoral enhancements}

Scotland has ambitions to reduce emissions, and move towards a greater use of renewable energy technologies. The most recent data show significant progress on electricity: in 2017, $68 \%$ of the electricity generated in Scotland came from renewable sources (Scottish Government, 2017c). This transition to renewable sources has not only resulted in reductions in Scotland's $\mathrm{CO}_{2}$ emissions, but has led to - as we saw in Section 4 - significant reductions in the water intensity associated with activity in the electricity. Global changes in energy policy toward increasing renewable resources have potential consequences for global water and food security, whereby the production of biofuel crops take up valuable land for food crop production and utilise vast quantities of water, especially in regions where water resources are already scarce.

However, the exploitation of natural (and renewable) energy resources, such as wind, have successfully reduced the volumes of water used in electricity generation. The recent closures of coal-fired plants such as Cockenzie and Longannet, resulted in a marked reduction in water demand in this sector. The further closure of existing nuclear facilities at Hunterston B in Ayrshire (planned for 2024), and Torness in East Lothian (2030) will also reduce the water intensity of the electricity supply sector.

Beyond the agricultural and energy sectors, reductions in water intensity across all economic sectors will be significant for future water security and the development of economic opportunities in Scotland. For example, the whisky sector is worth $£ 5$ billion per annum to the UK economy and is a sector that continues to expand with new distilleries and a growing tourism element improving annual economic performance (Scottish Environmental Protection Agency, 2018). Water is a critical part of the product and processes involved in all stages of the creation of whisky: while much of the produce 
is abstracted from nearby water sources, piped water supplies are used in the cleaning, cooling and supply to visitor facilities. A critical focus for the Scotch Whisky Association and Scottish Environmental Protection Agency (SEPA) is improving the water efficiency of distilleries by $10 \%$ by 2020 while concomitantly improving water quality, reducing impacts on river flows and developing resilience for future climate change (Scottish Environmental Protection Agency, 2018).

Reductions in the water intensity of output across economic sectors can be achieved via three main approaches: i) water pricing strategies (Berrittella et al., 2008), ii) increased efficiency in water allocation (Hoekstra, 2014), and iii) technological measures to reduce consumption and increase productivity to ensure maximum value per drop (Gleick, 1998). While many businesses across Scotland are already investing in technologies such as smart meters to reduce water consumption, more opportunities will continue to appear as new technologies are developed and distributed. Simple strategies, such as the installation of water saving systems (such as low-volume flush toilets, sensor taps, conveying systems and water treatment/reuse systems) have had demonstrable success in diverse situations, whereas sectoral specific processes can be enhanced to reduce the water associated with certain services or production processes. For example, Burkinshaw et al. (2011) highlighted an innovation in commercial laundry technology via the development of a polymer-bead washing machine that reduces water consumption by c. $80 \%$, reducing the water and energy costs associated with laundry-intensive sectors such as hotels, care homes and laundrettes. Similar technological advances across other sectors can result in significant reductions in water intensities and allow water to be used for higher-value outputs, maximising economic productivity while reducing the environmental footprints associated with certain activities.

A critical challenge is ensuring that improvements in water efficiency strategies translate to reductions in water intensity and a drop in usage volumes. Paradoxically, increasing the efficiency of water usage can result in increased activities in the more water- 
efficient sector and perhaps across the economy as a whole, as lower prices can result in an increase in the volumes being used. This "rebound effect" (also known as Jevons Paradox) has been demonstrated widely in the energy literature (e.g. Allan et al. (2007) and Gillingham et al. (2016)), and similar problems have increasingly been identified within the area of water research (Berbel et al., 2015). For example, the introduction of improved efficiencies in irrigation technologies in agricultural lands demonstrably lead to a rebound effect with regard to water use (e.g. Dumont et al. (2013) and Sears et al. (2018)). As a result, enhancing water use efficiency in a non-domestic setting may need to be tackled via a combined approach that utilises technology, education and policies (both regional and national) to ensure that genuine savings are being achieved.

\section{Conclusions}

Scotland's vast resources are under increasing threat from variable rainfall patterns as a result of global climate change. As decision makers in policy and industry seek to explore challenges and opportunities in the new climate future, there is a valuable role for models at the regional level which can link resource availability and use with economic frameworks, and so meaningfully relate environmental changes to economic impacts, and vice versa. Accessing and relating spatially relevant data is a major challenge for scientists across economic, environmental and climate domains.

In this paper we bring together a unique database on premise-level water use and sectoral economic indicators to perform the first Index Decomposition Analysis (IDA) to industrial water use in Scotland, covering the period between 2012 and 2016. IDA has become a dominant empirical technique for understanding changes in environmental variables, e.g. water demand, through both economic and technological dimensions. While its use has increased rapidly in the last decade in energy and environment fields, to our knowledge there have been only a handful of applications to water (i.e. Cazcarro 
et al. (2013); Kohler (2016); Shang et al. (2016, 2017a,b)) partly due to the lack of available water data at the sectoral level (Duarte and Yang, 2011).

While in headline, there is a significant reduction in aggregate measure of water intensity (i.e. water use $m^{3}$ per $£$ of Gross Value Added (GVA)) over this period, we see that almost all sectors see a reduction (improvement) in water intensity over this period. Our IDA results confirm that the structural effect - reflecting the evolved structure of the economy - reduces water demand, but not sufficiently to offset the increased economic activity effect. The major drivers of the decrease in non-domestic water use are improvements (reductions) in within sector water intensity. Between 2015 and 2016 water demand actually increased despite the closing of water-intensive elements within the electricity generation mix, demonstrating the critical need to consider all sectors in the economy when making forecasts of water demand.

Given variability in future water resources there will be greater pressure on water users to maximise the productivity of water. These steps will require firms as well as governments to better understand their use of water (both directly, and indirectly through water-intensive inputs), including water used in inputs from water-stressed areas. Scotland's water managers can learn from practices in areas where water stress is more common, such as California and the Mediterranean, particularly given its reliance upon rainfall as the primary source of water for critical economic activities, including agriculture, electricity and whisky. There does exist, however, a potential for there to be economic opportunities for regions where water is more abundant, but it requires a detailed understanding of the links between economic activity and water availability and use. Economic opportunities also exist from the implementation of new technologies to understand water consumption, water availability and to plan for greater efficiencies in the use of water across the economy.

This research could usefully be extended in a number of ways. First, understanding the economic opportunities from improving water management and use is fundamental 
to the Hydro Nation programme of the Scottish Government, which require a more detailed understanding of the ways in which all water is used in Scotland. In this paper, our data on water consumption omits non-mains sources, while rainfall and river sources are critical for many water uses in Scotland.

Second, we have focused on the domestic (i.e. Scottish) factors influencing water demand in Scotland. Water Footprint methods assign responsibility for water use to the act of consumption of goods and services produced anywhere in the world. On this basis, as an open economy Scotland is highly linked to markets in the UK and Europe ${ }^{16}$ and so it is likely that a significant element of Scotland's water consumption is servicing demands outside of the nation ${ }^{17}$. As such, changes in Scotland's water footprint would be driven by changes in its imports and exports, as well as the shifts in trade of waterintensive products.

Third, extending from the static measures of footprints, which typically use InputOutput (IO) techniques, there are an increasing number of applications of ex ante economic modelling that focus on water-economy links. These range from linear IO studies of water multipliers (e.g. Velazquez (2006); Blackhurst et al. (2010)) which compute water implications of demand-side changes, to more complex Computable General Equilibrium (CGE) frameworks where links between water input use and activity at the sectoral level are captured with greater sophistication, including being able to reflect price sensitivity, incorporating the substitutability between water and other inputs, and producing economic and water indicators (Markandya (2017); Berbel et al. (2015); Wittwer (2012)). These approaches offer significant potential to explore fundamental connectedness between water availability and use and economic use, which is critical to identifying economic consequences and opportunities from a changing climate.

\footnotetext{
${ }^{16}$ Fraser of Allander Institute (2017) noted that 890,000 jobs in Scotland are currently supported by export demand from the rest of the UK, the EU and the rest of the world.

${ }^{17} \mathrm{~A}$ full water footprint would add the water attributable to a nations own consumption of domestically-produced goods to water embodied in goods imported for consumption, while subtracting water used domestically in the production of exports.
} 


\section{Acknowledgments}

The authors acknowledge the assistance of Scottish Water without which this research would not be possible. Allan, McGrane and Roy acknowledge the funding from the University of Strathclyde through the Global Engagement Fund, which enabled the authors to spend time at Stanford University, where the initial draft of the paper was

produced in March/April 2018. Any errors and omissions remain the responsibility of the authors. 
Table 1: Data on industrial/sectoral economic characteristics and water-intensities, 2012 and 2016

\begin{tabular}{|c|c|c|c|c|}
\hline & \multirow{2}{*}{\multicolumn{2}{|c|}{ GVA shares $(\%)$}} & \multirow{2}{*}{\multicolumn{2}{|c|}{ Water intensities (m3 per £1mGVA) }} \\
\hline & & & & \\
\hline & 2012 & 2016 & 2012 & 2016 \\
\hline Agriculture, Forestry and Fishing & $1.53 \%$ & $1.79 \%$ & 6,098 & 4,704 \\
\hline Mining and Quarrying Industries & $1.92 \%$ & $1.75 \%$ & 1,082 & 979 \\
\hline Food, Beverages and Tobacco & $2.87 \%$ & $2.91 \%$ & 4,251 & 3,682 \\
\hline Textiles, Clothing and Leather Products & $0.39 \%$ & $0.41 \%$ & 2,173 & 1,854 \\
\hline Refined Petroleum, Chemical and Pharmaceutical Products & $1.47 \%$ & $1.27 \%$ & 15,010 & 13,305 \\
\hline Metals, Metal Products and Machinery n.e.c. & $1.89 \%$ & $1.61 \%$ & 869 & 620 \\
\hline Computer, Electrical and Optical Products & $0.91 \%$ & $0.89 \%$ & 906 & 482 \\
\hline Transport Equipment & $0.62 \%$ & $0.69 \%$ & 288 & 152 \\
\hline Other Manufacturing Industries; Repair and Installation & $2.51 \%$ & $2.37 \%$ & 2,425 & 2,341 \\
\hline Electricity and Gas Supply & $2.73 \%$ & $2.33 \%$ & 3,598 & 3,044 \\
\hline Water Supply and Waste Management & $1.36 \%$ & $1.39 \%$ & 1,201 & 1,356 \\
\hline Construction & $6.34 \%$ & $7.52 \%$ & 248 & 145 \\
\hline Retail and Wholesale & $10.53 \%$ & $10.55 \%$ & 733 & 528 \\
\hline Accommodation and Food Services & $3.14 \%$ & $3.14 \%$ & 3,861 & 3,411 \\
\hline Transport, Information and Communication & $7.57 \%$ & $7.87 \%$ & 871 & 750 \\
\hline Financial and Insurance Activities & $6.58 \%$ & $6.45 \%$ & 250 & 168 \\
\hline Real Estate Activities & $10.69 \%$ & $10.96 \%$ & 68 & 67 \\
\hline Professional, Scientific, Administrative and Support Services & $9.92 \%$ & $10.62 \%$ & 376 & 252 \\
\hline Public Administration and Defence & $6.82 \%$ & $6.12 \%$ & 1,560 & 1,538 \\
\hline Education & $6.63 \%$ & $6.28 \%$ & 631 & 677 \\
\hline Health and Social Work & $9.81 \%$ & $9.47 \%$ & 867 & 745 \\
\hline \multirow[t]{2}{*}{ Other Services } & $3.77 \%$ & $3.59 \%$ & 1,274 & 1,056 \\
\hline & $100.00 \%$ & $100.00 \%$ & & \\
\hline
\end{tabular}




\section{References}

Ajiero, I. and Campbell, D. (2018). Benchmarking water use in the uk food and drink sector: Case study of three water-intensive dairy products. Water Conservation Science and Engineering, 3(1):1-17.

Allan, G., Hanley, N., McGregor, P., Swales, K., and Turner, K. (2007). The impact of increased efficiency in the industrial use of energy: A computable general equilibrium analysis for the United Kingdom. Energy Economics, 29(4):779-798.

Ang, B. (2015). LMDI decomposition approach: a guide for implementation. Energy Policy, 86:233-238.

Ang, B. W. (2004). Decomposition analysis for policymaking in energy:: which is the preferred method? Energy policy, 32(9):1131-1139.

Ang, B. W. and Zhang, F. Q. (2000). A survey of index decomposition analysis in energy and environmental studies. Energy, 25(12):1149-1176.

Barnett, C., Hossell, J., Perry, M., Procter, C., and Hughes, G. (2006). A handbook of climate trends across Scotland. Technical report.

Berbel, J., Gutiérrez-Martín, C., Rodríguez-Díaz, J. A., Camacho, E., and Montesinos, P. (2015). Literature review on rebound effect of water saving measures and analysis of a Spanish case study. Water Resources Management, 29(3):663-678.

Berrittella, M., Rehdanz, K., Roson, R., and Tol, R. S. J. (2008). The economic impact of water taxes: a computable general equilibrium analysis with an international data set. Water Policy, 10(3):259.

Betts, R. A., Alfieri, L., Bradshaw, C., Caesar, J., Feyen, L., Friedlingstein, P., Gohar, L., Koutroulis, A., Lewis, K., Morfopoulos, C., et al. (2018). Changes in climate 
extremes, fresh water availability and vulnerability to food insecurity projected at $1.5^{\circ} \mathrm{C}$ and $2^{\circ} \mathrm{C}$ global warming with a higher-resolution global climate model. Phil . Trans. R. Soc. A, 376(2119):20160452.

Blackhurst, B. M., Hendrickson, C., and Vidal, J. S. I. (2010). Direct and indirect water withdrawals for US industrial sectors. Environmental science 8$\}$ technology, $44(6): 2126-2130$.

Brown, I., Dunn, S., Matthews, K., Poggio, L., Sample, J., and Miller, D. (2011). Mapping of water supply-demand deficits with climate change in Scotland: land use implications. CREW report.

Burkinshaw, S., Howroyd, J., Kumar, N., and Kabambe, O. (2011). The wash-off of dyeings using interstitial water: Part 3. disperse dyes on polyester. Dyes and Pigments, 91(3):340-349.

Cazcarro, I., Duarte, R., and Sánchez-Chóliz, J. (2013). Economic growth and the evolution of water consumption in Spain: A structural decomposition analysis. Ecological Economics, 96:51-61.

Chan, S. C., Kahana, R., Kendon, E. J., and Fowler, H. J. (2018). Projected changes in extreme precipitation over scotland and northern england using a high-resolution regional climate model. Climate Dynamics, 51(9):3559-3577.

Chartzoulakis, K. and Bertaki, M. (2015). Sustainable water management in agriculture under climate change. Agriculture and Agricultural Science Procedia, 4:88-98.

Claret, C., Metzger, M. J., Kettunen, M., and ten Brink, P. (2018). Understanding the integration of ecosystem services and natural capital in Scottish policy. Environmental Science ES Policy, 88:32 - 38 . 
Duarte, R. and Yang, H. (2011). Input-output and water: introduction to the special issue. Economic Systems Research, 23(4):341-351.

Dumont, A., Mayor, B., and López-Gunn, E. (2013). Is the rebound effect or jevons paradox a useful concept for better management of water resources? Insights from the irrigation modernisation process in Spain. Aquatic Procedia, 1:64-76. At the Confluence - Selection from the 2012 World Water Week in Stockholm.

Ferrier, R. C. and Edwards, A. C. (2002). Sustainability of Scottish water quality in the early 21st Century. Science of The Total Environment, 294(1):57-71. Hydrology in Scotland: towards a scientific basis for the sustainable management of freshwater resources.

Fraser of Allander Institute (2017). Brexit and the sectors of the Scottish economy. Technical report.

Gillingham, K., Rapson, D., and Wagner, G. (2016). The rebound effect and energy efficiency policy. Review of Environmental Economics and Policy, 10(1):68-88.

Gleick, P. H. (1998). Water in crisis: Paths to sustainable water use. Ecological Applications, 8(3):571-579.

Gosling, R. (2014). Assessing the impact of projected climate change on drought vulnerability in Scotland. Hydrology Research, 45(6):806.

Gowdy, J. M. and Miller, J. L. (1987). Technological and demand change in energy use: an input - output analysis. Environment and planning a, 19(10):1387-1398.

Grubert, E. and Sanders, K. T. (2018). Water use in the United States energy system: A national assessment and unit process inventory of water consumption and withdrawals. Environmental Science 83 Technology, 52(11):6695-6703.

Hannaford, J. (2018). Uk hydrological status update - early July 2018. Technical report. 
Henderson, J., Rodgers, C., Jones, R., Smith, J., Strzepek, K., and Martinich, J. (2015). Economic impacts of climate change on water resources in the coterminous United States. Mitigation and Adaptation Strategies for Global Change, 20(1):135-157.

Hoekstra, A. Y. (2014). Sustainable, efficient, and equitable water use: the three pillars under wise freshwater allocation. Wiley Interdisciplinary Reviews: Water, 1(1):31-40.

Hoekstra, R. and Van den Bergh, J. C. (2003). Comparing structural decomposition analysis and index. Energy economics, 25(1):39-64.

Kampragou, E., Apostolaki, S., Manoli, E., Froebrich, J., and Assimacopoulos, D. (2011). Towards the harmonization of water-related policies for managing drought risks across the EU. Environmental Science $\&$ Policy, 14(7):815 - 824.

Kohler, M. (2016). Confronting South Africa's water challenge: a decomposition analysis of water intensity. South African Journal of Economic and Management Sciences, $19: 831-847$.

Lowe, J., Bernie, D., Bett, P., Bricheno, L., Brown, S., Calvert, D., Clark, R., Eagle, K., Edwards, T., Fosser, G., Fung, F., Gohar, L., Good, P., Gregory, J., Harris, G., Howard, T., Kaye, N., Kendon, E., Krijnen, J., Maisey, P., McDonald, R., McInnes, R., McSweeney, C., Mitchell, J., Murphy, J., Palmer, M., Roberts, C., Rostron, J., Sexton, D., Thornton, H., Tinker, J., Tucker, S., Yamazaki, K., and Belcher, S. (2018). Ukcp18 science overview report. Technical report.

Markandya, A. (2017). State of knowledge on climate change, water, and economics. Technical report.

Marsh, T. and Anderson, J. (2002). Assessing the water resources of Scotland: Perspectives, progress and problems. Science of The Total Environment, 294(1):13-27. 
Mekonnen, M. and Hoekstra, A. Y. (2011). National water footprint accounts: the green, blue and grey water footprint of production and consumption.

Miller, R. E. and Blair, P. D. (2009). Input-Output analysis: foundations and extensions. Cambridge University Press, Cambridge.

National Records of Scotland (2016). Projected population of Scotland (2016-based) key findings. Technical report.

National Records of Scotland (2018). Mid-year population estimates: Scotland 2018. Technical report.

O'Connor, A. (2018). Brewing and distilling in Scotland -economic facts and figures: SPICe briefing 18-64. Technical report.

Organisation for Economic Development and Cooperation (2012). What could the environment look like in 2050? Technical report.

Ranganathan, J., Vennard, D., Waite, R., Dumas, P., Lipinski, B., and Searchinger, T. (2016). Shifting diets for a sustainable food future. World Resources Institute.

Robins, L., Burt, T., Bracken, L., Boardman, J., and Thompson, D. (2017). Making water policy work in the United Kingdom: A case study of practical approaches to strengthening complex, multi-tiered systems of water governance. Environmental Science 8 Policy, 71:41 - 55.

Rose, A. and Casler, S. (1996). Input-output structural decomposition analysis: a critical appraisal. Economic Systems Research, 8(1):33-62.

Scottish Environmental Protection Agency (2018). Scotch whisky sector plan. Technical report.

Scottish Government (2012). Scotland The Hydro Nation: Prospectus and Proposals for Legislation. Technical report. 
Scottish Government (2014). Climate Ready Scotland: Scottish Climate Change Adaptation Programme. Technical report.

Scottish Government (2015). Scotland's Economic Strategy: The future of energy in Scotland. Technical report.

Scottish Government (2017a). Public Water Supplies, 2002/03 to 2016/17. Technical report.

Scottish Government (2017b). Scottish Energy Strategy: The future of energy in Scotland. Technical report.

Scottish Government (2017c). Scottish Energy Strategy: The future of energy in Scotland. Technical report.

Sears, L., Caparelli, J., Lee, C., Pan, D., Strandberg, G., Vuu, L., and Lin Lawell, C. Y. C. (2018). Jevons' paradox and efficient irrigation technology. Sustainability, 10(5).

Shang, Y., Lu, S., Li, X., Sun, G., Shang, L., Shi, H., Lei, X., Ye, Y., Sang, X., and Wang, H. (2017a). Drivers of industrial water use during 2003-2012 in Tianjin, China: A structural decomposition analysis. Journal of Cleaner Production, 140:1136 - 1147.

Shang, Y., Lu, S., Shang, L., Li, X., Shi, H., and Li, W. (2017b). Decomposition of industrial water use from 2003 to 2012 in Tianjin, China. Technological Forecasting and Social Change, 116:53-61.

Shang, Y., Lu, S., Shang, L., Li, X., Wei, Y., Lei, X., Wang, C., and Wang, H. (2016). Decomposition methods for analyzing changes of industrial water use. Journal of Hydrology, 543:808-817.

Su, B. and Ang, B. (2012). Structural decomposition analysis applied to energy and emissions: some methodological developments. Energy Economics, 34(1):177-188. 
Trivedi, M. R., Browne, M. K., Berry, P. M., Dawson, T. P., and Morecroft, M. D. (2007). Projecting climate change impacts on mountain snow cover in central Scotland from historical patterns. Arctic, Antarctic, and Alpine Research, 39(3):488-499.

Velazquez, E. (2006). An input-output model of water consumption: analysing intersectoral water relationships in Andalusia. Ecological Economics, 56(2):226-240.

Wang, H., Ang, B., and Su, B. (2017). Assessing drivers of economy-wide energy use and emissions: IDA versus SDA. Energy Policy, 107:585-599.

Werritty, A. (2002). Living with uncertainty: climate change, river flows and water resource management in Scotland. Science of the Total Environment, 294:29-40.

Wittwer, G. (2012). Economic modeling of water: the Australian CGE experience. Springer Science \& Business Media, Dordrecht.

Xu, Y., Huang, K., Yu, Y., and Wang, X. (2015). Changes in water footprint of crop production in Beijing from 1978 to 2012: a logarithmic mean Divisia index decomposition analysis. Journal of Cleaner Production, 87:180-187.

Zhang, Z., Shi, M., and Yang, H. (2012). Understanding Beijing's Water Challenge: A Decomposition Analysis of Changes in Beijing's Water Footprint between 1997 and 2007. Environmental Science \& Technology, 46(22):12373-12380.

Zhao, X., Tillotson, M., Liu, Y., Guo, W., Yang, A., and Li, Y. (2017). Index decomposition analysis of urban crop water footprint. Ecological Modelling, 348:25-32. 